\title{
Clarissa Raposo* \\ A Política de Atenção Integral à Saúde do Adolescente e Jovem: uma perspectiva de garantia de direito à saúde?
}

Resumo: o texto analisa a interface entre o paradigma dos direitos da infância
e adolescência no Brasil (Estatuto da Criança e do Adolescente - ECA) e a
legislação do Sistema Único de Saúde (SUS). Destacando as diretrizes de
municipalização/descentralização, o atendimento integral, a participação da
comunidade, e os princípios de universalidade, integralidade e igualdade,
situa a política de saúde do adolescente, identifica as suas diretrizes e os
eixos prioritários de ação e reflete sobre os seus delineamentos no contexto
atual de precarização do financiamento, gestão e serviços do SUS. Relaciona
as formas de violação do direito à saúde e a vulnerabilidade na adolescência
como expressões contundentes de um contexto de transformações estruturais
operadas sob a crise do capitalismo contemporâneo. Defende a perspectiva
crítica e analítica marxiana para compreender a realidade contemporânea e
desmistificar a concepção liberal de política social como direito de cidadania,
para que esta seja entendida como meio (e não como um fim) para construção
de uma sociedade igualitária.
Palavras-Chave: Estatuto da Criança e do Adolescente; Política Social; Saúde

Abstract: this text approaches the new standard of childhood and adolescence wrights in Brazil, the Statute of the Child and of the Adolescent (ECA). The author evidences the common traces between the aforesaid Statute and the legislation of the Unified Health System (SUS): the guidelines of the municipalization/descentralization, integral service and the community participation and the principles of universality, integrality and equality. It is pointed out the adolescent's health policy, identifying its guidelines and prioritarian targets of action, also pondering about its outlines in the nowadays context of precarization of the SUS. It Indicates the dimensions of the violation means of the wright to health, and the vulnerable in the adolescence as incisive expressions of a context of structural changes trigged by the new logic imposed upon the crisis of contemporary Capitalism. It defends the perspective of critical analisys based upon Marxism to understand the complex logic of contemporary reality. It tries to desmystify the concept of social policy as wright of citizenship, so that it could be understood as a way - not as an aim - towards the construction of a new society.

Keywords: Statute of the Child and of the Adolescent, social policy, health, Unified Health System, contemporary changes, citizenship. 


\section{ReVISta Em Pauta}

A inserção na agenda pública brasileira da atenção integral à saúde de adolescentes e jovens decorre da mudança de paradigma expressa na concepção ampliada de saúde como direito social e dever do Estado e na doutrina da proteção integral preconizada pelo Estatuto da Criança e do Adolescente (ECA).

A Lei do Estatuto da Criança e do Adolescente (ECA) regulamenta a proteção da infância e da adolescência e reconhece as crianças e os adolescentes como sujeitos de direitos e portadores de necessidades especiais. Nesse sentido, este marco legal configura uma perspectiva de análise para contextualização dos direitos da adolescência e juventude no âmbito da saúde.

A Política de Saúde do Adolescente e Jovem institucionaliza um novo olhar sobre o adolescente, apresentando arcabouço teórico que estimula a reflexão sobre novos conceitos, estratégias e ações na área de promoção da saúde voltada para esse grupo etário.

A Política Nacional de Saúde do Adolescente e Jovem preconiza a atenção integral a esse segmento populacional, considerando as necessidades específicas de adolescentes e jovens, as características socioeconômicas e culturais da comunidade à qual pertencem, bem como as diferenças de gênero, raça e religião.

Desse modo, o modelo de atenção à saúde do adolescente e jovem, resultante de uma política pública integrada à Política Nacional de Saúde e articulada a outros setores governamentais e não governamentais, reflete a perspectiva de intervenção do Estado na garantia e efetivação dos direitos sociais regulamentados pelo marco legal da Lei 8.080/90, que dispõe sobre os princípios e diretrizes do Sistema Único de Saúde (SUS), e da Lei 8.069/90, do Estatuto da Criança e do Adolescente (ECA).

Contudo, as atuais dimensões da violação dos direitos sociais e as situações de vulnerabilidade são expressões contundentes das transformações decorrentes da crise estrutural do capitalismo contemporâneo, evidenciadas pela fragilização das ações de proteção pública do Estado brasileiro expressa na focalização e privatização das políticas sociais, bem como pela transferência de responsabilidades com a execução dos gastos sociais para o terceiro setor.

Nesse cenário, os programas voltados para saúde enfrentam dificuldades para integrar as ações e serviços de saúde ao Sistema Único de Saúde (SUS) e garantir a cobertura adequada para a população de adolescentes e jovens. Os dilemas daí decorrentes serão considerados neste texto a partir de três questões interrelacionadas. A primeira relativa a relação direito à saúde, pressupostos legais contidos no Estatuto da Criança e do Adolescente (ECA) e princípios norteadores da Legislação do Sistema Único de Saúde (SUS). Pretende-se evidenciar a integralidade e a descentralização como traços comuns dessas legislações.

A segunda questão é representada pelo novo modelo de atenção à saúde de adolescentes e jovens, a partir da Política Nacional de Atenção Integral à Saúde do Adolescente e Jovem, procurando refletir sobre os seguintes aspectos: as diretrizes de operacionalização dessa política, os eixos prioritários de ação e a temática da promoção de saúde.

A terceira questão envolve a caracterização da violação do direito à saúde de crianças e adolescentes e das situações de vulnerabilidade, dimensionadas no contexto de crise do Estado brasileiro, visando a problematizar os dilemas e as 

atuais perspectivas das políticas sociais em face das profundas mudanças vivenciadas no capitalismo contemporâneo.

A saúde como um direito do adolescente - convergências entre a legislação do Sistema Único de Saúde (SUS) e o Estatuto da Criança e do Adolescente

O momento de redemocratização do país, vivenciado no Brasil a partir da década de 1980, revela mudanças significativas na história da assistência à infância e a adolescência, ao tempo que se inaugura a "era dos direitos". No caso específico da criança e do adolescente, estes passaram a ser considerados sujeitos de direitos em oposição a objetos de tutela e proteção por parte do Estado. Com efeito, o Estatuto aponta a necessidade de políticas sociais básicas e programas de apoio e desenvolvimento integral das crianças e adolescentes.

O novo direito da infância e juventude e os mecanismos de garantia dos direitos tomam como referência a doutrina da proteção integral estabelecida pelo Estatuto da Criança e do Adolescente. Com efeito, as mudanças na legislação da infância, decorrentes da elaboração e aprovação do Estatuto da Criança e do Adolescente, consubstanciadas na doutrina de proteção integral, assinalam uma nova etapa na história dos direitos da criança e do adolescente, ao tempo em que elevam os "menores" à condição de cidadãos e sujeitos de direitos, tal como preceitua o ECA, em seu Art. 1": "Esta lei dispõe sobre a proteção integral à criança e ao adolescente".

O Estatuto tem por objetivo a proteção integral da criança e do adolescente, de tal forma que cada brasileiro que nasce possa ter assegurado seu pleno desenvolvimento, levando-se em conta aspectos físicos, mentais, culturais e espirituais. Sobre isso, é que se pode afirmar: "A idéia de proteção integral está calçada (...) no reconhecimento de que a vulnerabilidade própria da idade exige uma forma específica de proteção, traduzida em direitos, individuais e coletivos, que possam assegurar seu pleno desenvolvimento." (GUARA apud RAPOSO, 2003, p. 45).

Neste sentido, o Estatuto é considerado o instrumento para salvaguardar a vida e garantir o desenvolvimento pleno das crianças e adolescentes brasileiros. Assim, "a lei há de contribuir para a mudança de mentalidade na sociedade, habituada, infelizmente, a se omitir diante das injustiças de que são vítimas as crianças e adolescentes" (ALMEIDA apud RAPOSO, 2003, p. 45). Acredita-se que no horizonte deste estatuto nascerá uma nova sociedade, capaz de vencer a discriminação, a violência e a exploração da pessoa humana, marcada pela justiça, solidariedade e harmonia entre todos os cidadãos.

Como acentua Costa: "O Estatuto é o reflexo, no direito brasileiro, dos avanços em favor da Infância e Juventude. Ele representa uma parte importante do esforço de uma Nação,

recém-saída de uma ditadura de duas décadas, para acertar o passo com a comunidade internacional em termos de direitos humanos" (PORTO apud RAPOSO, 2003, p. 9).

O Estatuto promoveu mudanças significativas na política de atendimento à infância e adolescência ao propor um novo sistema articulado e integrado de atenção 

a todas as necessidades da criança e do adolescente e a garantia de seus direitos. De acordo com o texto constitucional, o ECA declara no Art.3": "A criança e o adolescente gozam de todos os direitos fundamentais inerentes à pessoa humana, sem prejuízo da proteção integral".

No campo do Direito, o Estatuto inaugura a especialização do direito da infância e da juventude, proclamando a situação jurídica da menoridade com o tratamento legal inerente a essa condição humana. Logo, "pode-se dizer que o Direito da Infância e da Juventude, sem embargo de algumas marcas de Direito privado que não chegam a alterar a sua natureza, é especialmente um ramo novo do Direito público, da categoria dos direitos humanos fundamentais" (TAVARES, apud RAPOSO, 2003, p. 45). Em suma, o Direito da Infância e da Juventude no Brasil está incluído na categoria dos direitos humanos fundamentais de terceira geração.

O Estatuto preconiza como direitos fundamentais das crianças e adolescentes: o direito à vida e à saúde 1 , à liberdade, ao respeito e à dignidade, à convivência familiar e comunitária, à educação, cultura, esporte e lazer, e à profissionalização e proteção no trabalho. O ECA estabelece o direito à vida e à saúde como um dos cinco direitos fundamentais garantidos a todas as crianças e adolescentes brasileiros.

De acordo com o art. $4^{\circ}$ desta lei:

É dever da família, da comunidade, da sociedade em geral e do Poder Público assegurar, com absoluta prioridade, a efetivação dos direitos referentes à vida, à saúde, à alimentação, à educação, ao esporte, ao lazer, à profissionalização, à cultura, à dignidade, ao respeito, à liberdade e à convivência familiar e comunitária.

Com base nessas considerações, objetivamos contribuir para o debate sobre a garantia dos direitos sociais da infância e juventude na área de saúde; para tanto, nossa análise será delineada a partir das seguintes questões: $O$ direito à vida e à saúde com base na legislação do Sistema Único de Saúde (SUS) e os dispositivos legais do ECA que tratam do direito à saúde para infância e juventude, procurando analisar os traços comuns dessas duas legislações.

Inicialmente, destacamos que a legislação do Sistema Único de Saúde (SUS) prevê a integração de uma rede regionalizada e hierarquizada, organizada de acordo com as seguintes diretrizes: descentralização, atendimento integral e participação da comunidade.

A descentralização das ações e serviços de saúde reflete uma forma de organização que dá aos municípios o poder de administrar os serviços de saúde locais. O atendimento integral confere prioridade às atividades preventivas, sem prejuízo dos serviços assistenciais, e a participação da comunidade pressupõe o direito de todo cidadão participar dos Conselhos de Saúde nos diferentes níveis

$1 \mathrm{O}$ Direito à saúde constitui um direito humano fundamental que exclui qualquer outra norma que se mostre prejudicial ao bem juridicamente tutelado à saúde da pessoa humana. 

formulação, controle e gestão dos serviços de saúde.

Entre os princípios que regem os serviços que integram o Sistema Único de Saúde (SUS), destacam-se:

I - universalidade de acesso aos serviços de saúde em todos os níveis de assistência;

II - a integralidade de assistência, entendida como um conjunto articulado e contínuo das ações e serviços preventivos e curativos, individuais e coletivos, exigidos para cada caso em todos os níveis de complexidade do sistema; III - preservação da autonomia das pessoas na defesa de sua integridade física e moral;

IV - igualdade na assistência à saúde, sem preconceitos ou privilégios de qualquer espécie; (Lei Orgânica da Saúde - Lei 8.080 de 19/09/1990 apud BRASIL, 2005, p. 14).

O Estatuto da Criança e do Adolescente (ECA) assegura o atendimento médico à criança e ao adolescente por meio do Sistema Único de Saúde, e o acesso universal e igualitário às ações e serviços para promoção, proteção e recuperação da saúde (CURY, 2002). Desse modo, o direito passa a ser concebido de uma forma mais ampla, na medida em que abrange a proteção, a promoção e a recuperação da saúde.

Tal como se pode ver, alguns princípios do Sistema Único de Saúde (SUS) expressam uma relação direta com a política de atendimento à infância e à adolescência determinada pelo Estatuto de Criança e do Adolescente (ECA).

A garantia do direito à Saúde remete à efetivação da política de atendimento para a infância e adolescência, conforme as diretrizes estabelecidas pelo ECA. Não obstante, a efetivação do direito à saúde pressupõe a articulação de uma rede regionalizada e descentralizada dos serviços de saúde, os quais devem ser regidos pelos princípios de universalidade, integralidade e igualdade, conforme previsto na legislação do SUS .

A efetivação dos princípios da universalidade e igualdade perpassa a implantação de uma política descentralizada e articulada, cujo modelo se encontra delineado pela da legislação do SUS e do Estatuto. Por consequência, esse modelo descentralizado sinaliza a importância da integração operacional de diversos órgãos para a efetivação do atendimento integral e prioritário da criança e do adolescente.

Com a implantação das Normas Operacionais Básicas do SUS-NOB-SUS 91, e das NOB-SUS 93 e 96, cujo principal objetivo era promover a integração de ações entre as três esferas de governo, desencadeou-se um processo intenso de descentralização, transferindo, principalmente para os municípios, um conjunto de responsabilidades e recursos para a operacionalização do SUS (CRESS, 2002, p. 235). Apesar de alguns avanços significativos na organização de redes articuladas e resolutivas de serviços, à medida que o processo de gestão descentralizada avançava, surgia um conjunto de problemas e entraves para a consolidação do SUS. Atualmente, esses problemas se tornam cada vez mais complexos e se colocam 

na contramão da garantia do acesso aos serviços de saúde, configurando verdadeiros obstáculos à universalidade e à integralidade, princípios do sistema.

O Estatuto da Criança e do Adolescente reserva capítulo próprio ao direito à saúde, que deve ser garantido por meio do SUS, prioritariamente: "atendimento médico, farmacêutico e outros recursos para tratamento e reabilitação; promoção de programas de assistência médica e odontológica para a prevenção dos agravos do segmento infanto-juvenil; vacinação obrigatória; permanência dos pais ou responsáveis junto com a criança e o adolescente em casos de internação." (BRASIL, MINISTÉRIO DA SAÚDE, 2005, p. 32).

Em seu conteúdo, o ECA estabelece novas diretrizes para ações públicas de atendimento para a infância e a juventude, com diretrizes similares às do SUS: descentralização e municipalização do atendimento; controle social e participação da comunidade por meio de Conselhos de Direitos e Conselhos Tutelares; manutenção de recursos específicos por intermédio dos fundos municipais, estaduais e nacionais ligados aos respectivos Conselhos de Defesa; integração operacional de diversos órgãos para agilidade do atendimento.

Especificamente com relação ao direito à vida e à saúde: "A criança e o adolescente têm direito à proteção à vida e à saúde, mediante a efetivação de políticas sociais públicas que permitam o desenvolvimento sadio, harmonioso, em condições dignas de existência" (CURY, 2002, p.41).

No âmbito da saúde, o Estatuto da Criança e do Adolescente assegura a prioridade absoluta às ações e serviços que atendam às necessidades das crianças e adolescentes e contribuam para o seu desenvolvimento sadio e harmonioso. "É dever da família, da sociedade em geral e do Poder público assegurar, com absoluta prioridade, a efetivação dos direitos à vida, à saúde (...)" (BRASIL, MINISTÉRIO DA SAÚDE, 2005, p. 15).

Parágrafo único. A garantia de prioridade compreende:

a) primazia de receber proteção e socorro em quaisquer circunstâncias;

b) precedência de atendimento nos serviços públicos ou de relevância pública;

c) preferência na formulação e na execução das políticas sociais públicas;

d) destinação privilegiada de recursos públicos nas áreas relacionadas com a proteção à infância e à juventude. (BRASIL, MINISTÉRIO DA SAÚDE, 2005, p.15).

Contudo, a recomendação de "prioridade absoluta" pelo Estatuto da Criança e do Adolescente e os avanços preconizados pelo SUS ainda não alcançaram de forma efetiva esse segmento populacional.

Constata-se que os adolescentes e jovens não têm sido atendidos em suas necessidades de saúde, assim como os serviços de saúde encontram dificuldades para atendimento às demandas específicas colocadas por esse grupo etário.

Seguindo a perspectiva analítica dos direitos da Infância e Adolescência no âmbito da saúde, o Art. $8^{\circ}$ do Estatuto da Criança e do Adolescente destaca: 
É assegurado à gestante, através do Sistema Único de Saúde, o atendimento pré e perinatal.

$\S 1$ 을 gestante será encaminhada aos diferentes níveis de atendimento, segundo critérios médicos específicos, obedecendo-se aos princípios de regionalização e hierarquização do sistema.

$\S 2^{\circ}$ A parturiente será atendida preferencialmente pelo mesmo médico que a acompanhou na fase pré-natal.

$\S 3^{\circ}$ Incumbe ao Poder Público propiciar apoio alimentar à gestante e a nutriz que dele necessitem. (CURY, 2002, p. 4243).

Como se pode observar, a lei assegura o acompanhamento médico durante a gravidez e, a seguir, até o primeiro ano de vida do recém-nascido, em visitas periódicas, visando com isso, principalmente, "diminuir os fatores de risco associados às altas taxas de complicações na gravidez, parto e puerpério" (EINSENSTEIN apud CURY, 2002, p.44). No entanto, alguns fatores como prematuridade, baixo peso para a idade gestacional, deficiências nutricionais, anomalias congênitas, depressão puerperal, falta de amamentação, são apontados como causas mais comuns de mortalidade e morbidade perinatal, que podem ser prevenidas através da atenção e cuidados primários e secundários de saúde².

Sob este aspecto, a gravidez na adolescência merece destaque especial no debate sobre o direito à saúde de adolescentes e jovens ${ }^{3}$. Atualmente, a "captação precoce de adolescentes grávidas" é recomendada como uma estratégia eficaz para prevenção da mortalidade materna e neonatal e preconizada pelo Ministério da Saúde e pela área técnica responsável pela Política de Atenção à Saúde do Adolescente. Contudo, na maioria das vezes, é inviabilizada pelo despreparo dos profissionais e pela desqualificação dos serviços de saúde para o atendimento diferenciado ao adolescente. Ou seja, comumente, as adolescentes e jovens do sexo feminino são atendidas nos serviços de pré-natal, parto e puerpério, integrantes da rede SUS, sem que haja uma assistência qualificada e diferenciada para usuárias adolescentes.

Outra questão que deve ser analisada no âmbito legal do direito à saúde de adolescentes refere-se à questão da hospitalização. De acordo com a lei, "os estabelecimentos de atendimento à saúde deverão proporcionar condições para a permanência em tempo integral de um dos pais ou responsável, nos casos de internação de criança ou adolescente" (CURY, 2002, p. 52). Por meio desse

\footnotetext{
2 O Perfil Analítico das Mães Adolescentes (10 a 19 anos) no Município de Maceió no ano de 2006 registrou 3.628 nascimentos de mães na faixa de 10 a 19 anos, sendo $3.465(95,5 \%)$ de mães de 15 a 19 anos. O baixo peso ao nascer e o parto cesário revelaram tendência crescente. A idade menor que 15 anos, pré-natal com menos que sete (7) consultas e duração da gestação menor que trinta e sete (37) semanas foram causas de baixo peso ao nascer. Demonstrando os limites efetivos na implantação e efetividade dessas normas pragmáticas. 3 "As complicações da gravidez, e parto e puerpério são a sexta causa de óbito para as adolescentes entre 15-19 anos" (EISENSTEIN apud CURY, 2002, p. 44).
} 

pressuposto legal, a hospitalização sobressai como uma questão de direito e justiça social.

Entretanto, no momento atual, os estabelecimentos de atendimento à saúde e hospitais da rede SUS estão longe de possuir as condições ideais para permanência do acompanhante. Por conta disso, muitas vezes colocam-se resistências e dificuldades por parte da administração dos hospitais para assegurar o direito à permanência desse acompanhante por tempo integral.

A questão da violência doméstica e maus-tratos também está presente no âmbito legal e encontra-se inserida no capítulo "Do Direito à Vida e à Saúde". Sobre isso, cabe destacar: "Os casos de suspeita ou confirmação de maus-tratos contra criança ou adolescente serão obrigatoriamente comunicados ao Conselho Tutelar da respectiva localidade, sem prejuízo de outras providências legais" (CURY, 2002, p. 54). Os maus-tratos manifestam-se nas formas de violência física, sexual, psicológica ou podem ser por ação ou omissão, e, nesses casos, se caracterizam como negligência. O Estatuto considera maus-tratos um problema de saúde pública e determina, de forma inovadora, a obrigatoriedade de comunicação dos casos suspeitos ao Conselho Tutelar. No caso de maus-tratos no meio familiar, cabe aos profissionais de saúde fazer a notificação e recomendar ao Conselho Tutelar o atendimento e o aconselhamento dos pais ou responsáveis, e, diante da confirmação, a tomada de providências legais. A confirmação, na maioria dos casos, é feita por exame especial hospitalar ou médico privado.

Observa-se que a notificação de casos de violência ou maus-tratos praticados contra crianças e adolescentes ainda constitui um desafio para os profissionais dos serviços de saúde. Em geral, essa questão é confundida e tratada como questão de sigilo profissional. Apesar da exigência de notificação compulsória, muitas formas de violência são desconhecidas pelo Sistema de Saúde. Além disso, não há um fluxo de informações adequadas sobre as iniciativas planejadas no nível central das Secretarias Municipais de Saúde - por meio das gerências de Programas de Saúde da Criança e do Adolescente - às unidades e profissionais da rede, fornecendo subsídios necessários para a execução de procedimentos e indicação da notificação (BRASIL, MINISTÉRIO DA SAÚDE, 2002).

Apesar desse procedimento não ter sido incorporado pela maioria dos serviços que compõem o sistema de saúde, a notificação dos maus-tratos praticados contra crianças e adolescentes é obrigatória por lei federal e essa obrigatoriedade se estende a todo o território nacional.

Com base na análise dos marcos legais - Lei Orgânica da Saúde 8.080/90 e Estatuto da Criança e do Adolescente Lei 8.069/90 - podem-se pontuar algumas reflexões importantes.

Em primeiro lugar, observa-se que a descentralização política e administrativa (ênfase na atuação dos municípios) e a participação da sociedade na formulação de políticas aparecem como traços comuns dessas legislações. Nesse sentido, a intersetorialidade das políticas que compõem o sistema de proteção social é defendida como condição essencial para uma melhor articulação institucional e o desenvolvimento de programas e ações que promovam a garantia e efetivação do atendimento integral à infância e adolescência. 
Outra questão que merece reflexão, o direito da infância e da juventude constitui um arcabouço jurídico que contém princípios e dispositivos ${ }^{4}$. Estes dispositivos são aplicáveis às situações concernentes aos bens e interesses daquelas pessoas que se acham em condição peculiar de desenvolvimento. A essas pessoas, "consideradas em lei como hipossuficentes para arcarem com suas responsabilidades jurídicas"(TAVARES apud RAPOSO, 2003, p. 96), por se encontrarem em condição peculiar de desenvolvimento, a ordem jurídica oferece um conjunto de dispositivos e cuidados próprios da Doutrina da Proteção Integral.

No entanto, ainda que estejam definidos os direitos humanos fundamentais da infância e juventude brasileiras, verifica-se que no cotidiano esses direitos estão longe de ser garantidos.

O direito constitucional à saúde, a asserção de "prioridade absoluta" pelo Estatuto da Criança e do Adolescente, os avanços preconizados pelo Sistema Único de Saúde (SUS) e a legislação de saúde ainda não alcançaram de forma efetiva essa parcela populacional. Esse descompasso entre as garantias legais à saúde e a realidade cotidiana de adolescentes e de jovens se deve a múltiplos fatores, dentre os quais se destacam:
A tradicional ênfase em programas de saúde direcionados à mu- Iher e à criança; o mito de que as pessoas jovens não adoecem; o baixo percentual de profissionais da Atenção Básica ca- pacitados para o atendimento; a noção de que apenas os "es- pecialistas" e os centros de referência seriam suficientemente qualificados para atender às suas demandas; a falta de integração entre os serviços de saúde e as demais instituições públicas e não-governamentais que atendem à população jovem (BRASIL, MINISTÉRIO DA SAÚDE, 2006, p. 19-20).

A combinação de todos esses fatores aponta para a necessidade de incluir, de forma mais abrangente e efetiva, a saúde de adolescentes e jovens nos instrumentos de planejamento e gestão do Sistema Único de Saúde (SUS), como forma de concretizar as ações propostas para esta parcela da população.

\section{O Modelo de Atenção Integral à Saúde do Adolescente: um novo olhar} para o adolescente e jovem

Como foi analisado no item anterior, a institucionalização de normativas e instrumentos legais de proteção dos direitos desse segmento populacional permeia a trajetória de evolução da atenção à saúde do adolescente. Em âmbito nacional, destaca-se a de 1988 a Constituição brasileira, a qual dispõe em seu Art. 227:

É dever da família, da sociedade e do Estado assegurar à criança e ao adolescente, com absoluta prioridade, o direito à vida, à

\footnotetext{
${ }^{4}$ Entende-se por dispositivo as "normas que determinam, regulam e enquadram as decisões e as ações, e que definem o que pode e o que não pode ser feito, como agir e decidir. Trata-se de codificações, (...) formalizadas em leis, decretos, portarias..." (FALEIROS apud RAPOSO, 2003, p. 96).
} 
saúde, à alimentação, à educação, ao lazer à profissionalização, à cultura, à dignidade, ao respeito, à liberdade e à convivência familiar e comunitária, além de colocá-los a salvo de toda forma de negligência, discriminação e exploração, crueldade e opressão (BRASIL apud RAPOSO, 2003, p. 41).

Os princípios básicos da Convenção Internacional dos Direitos da Criança são incorporados nesse texto constitucional, principalmente no referido artigo. Na verdade, esse período da história brasileira é marcado destaca-se pela mobilização e pressão dos movimentos sociais pela elaboração de uma lei voltada às necessidades das novas gerações e que, de uma vez por todas, revogasse a velha legislação do período autoritário.

Em 1989 dá-se a criação do Prosad (Programa de Saúde do Adolescente) em 24 estados, o qual se caracterizava por um conjunto de ações desenvolvidas por centros de referência, com ênfase nas práticas educativas e na participação dos adolescentes como multiplicadores de saúde.

Dentre os principais avanços, destaca-se a aprovação do Estatuto da Criança e do Adolescente (1990), que traz uma importante mudança de paradigma, a doutrina da Proteção Integral e o reconhecimento de crianças e adolescentes como sujeitos de direitos e não como objeto de tutela do Estado, da família ou da sociedade.

Deve-se ressaltar que as mudanças decorrentes da Constituição de 88 e os resultados do processo de elaboração e aprovação do Estatuto da Criança e do Adolescente em 1990 postulam o fim das políticas de cunho repressivo e paternalista, uma vez que o Estatuto estabelece uma política de atendimento aos direitos da criança e do adolescente. Consequentemente, com a transição da ditadura à democracia, o paradigma corretivo dá lugar a um paradigma educativo, de direitos para a criança e o adolescente.

Em 1993, tivemos a criação das Normas de Atenção à Saúde Integral do Adolescente, subsidiada pelos princípios e diretrizes do SUS.

E finalmente, em 2005, deu-se o processo de mobilização coletiva da sociedade para a construção preliminar de uma política que respondesse às necessidades de saúde e aos anseios dos adolescentes e jovens brasileiros, a atual Política Nacional de Atenção Integral à Saúde de Adolescentes e Jovens.

Essa política reflete uma nova linha de reflexão da atenção à saúde do adolescente, principalmente por evidenciar a integralidade ${ }^{5}$ da atenção em consonância com um dos princípios do SUS, o que pressupõe o atendimento integral com prioridade para as atividades preventivas, sem prejuízo dos serviços assistenciais, e a organização de serviços para a execução dessas práticas de saúde, destacando a importância da promoção da saúde e a necessidade de estabelecer processos de trabalho intersetoriais e interdisciplinares.

\footnotetext{
"A integralidade é a condição primordial da assistência a adolescentes e jovens, tanto do ponto de vista da organização dos serviços em nível de complexidade (promoção, prevenção, atendimento agravos e doenças, e reabilitação), quanto da compreensão dos aspectos biopsicossociais que permeiam as necessidades de saúde desses grupos populacionais." (MINISTÉRIO DA SAÚDE, 2005:13).
} 
Subsidiada por uma concepção de saúde como direito a ser garantido pelo Estado e pelos princípios do SUS, a política estabelece um novo modelo de atenção à saúde do adolescente.

A execução da política prevê a intersetorialidade e participação de Estados, municípios e Distrito Federal, para que de forma integrada possam implementar e articular ações, programas e projetos em consonância com os princípios do SUS, visando à assistência de qualidade para a adolescência e juventude, respeitando as suas especificidades.

Essa política integrada à política nacional de saúde, articulada a outros setores governamentais e não governamentais, propõe uma mudança estratégica na atenção ao adolescente, dentro de um enfoque de promoção da saúde e de protagonismo juvenil". "Este modelo de atenção preconizado fundamenta-se na territorialidade, na instersetorialidade, na articulação de parcerias e na participação juvenil" (BRASIL, MINISTÉRIO DA SAÚDE, 2006, p. 23). Está ancorado nas práticas preventivas de educação em saúde, reorientação e reorganização dos serviços, no sentido de oferecer um olhar diferenciado para esse grupo populacional.

Atualmente, a saúde do adolescente tem representado um desafio para profissionais de diversas áreas, que, por meio de atuação multidisciplinar, buscam implementar uma metodologia eficaz para o atendimento desse segmento populacional.

A implementação dessa metodologia de ação supõe a operacionalização das diretrizes de uma política de atenção integral à saúde do adolescente e jovem, a qual preconiza uma mudança significativa na forma de prestação e organização dos serviços de saúde, para que estes ofereçam um conjunto de ações resolutivas e de qualidade aos adolescentes e jovens, respeitando as suas características biopsicossociais, seus problemas e necessidades de saúde.

Sendo assim, "o objetivo geral dessa política é promover a atenção integral à saúde de adolescentes e de jovens, de 10 a 24 anos, no âmbito da Política Nacional de Saúde, visando à promoção de saúde, à prevenção de agravos e à redução da morbimortalidade" (BRASIL, MINISTÉRIO DA SAÚDE, 2006, p. 11).

A mudança estratégica proposta por esse modelo de atenção destaca a importância das ações de promoção da saúde. A política de saúde do adolescente recomenda que "as ações de saúde destinadas a adolescentes e jovens serão permeadas por práticas educativas numa perspectiva participativa, emancipatória, multiprofissional, voltadas para a equidade e cidadania" (BRASIL, 2006, p. 11).

As questões prioritárias de atenção à saúde de adolescentes e jovens são: o crescimento e desenvolvimento saudáveis; a saúde sexual e reprodutiva; e a redução da morbimortalidade por violências e acidentes.

A promoção do crescimento e desenvolvimento saudáveis remete ao acompanhamento sistemático dos adolescentes pelas Unidades Básicas de Saúde, subsidiado pela utilização da Caderneta de Saúde do Adolescente, reconhecida como instrumento de cidadania para essa população. Além disso, as ações

\footnotetext{
"O conceito de protagonismo juvenil busca uma forma de ajudar o adolescente e o jovem a construir sua autonomia, através da geração de espaços e situações propiciadoras da sua participação criativa, construtiva e solidária, na solução de problemas reais na escola, na comunidade e na vida social mais ampla" (BRASIL, MINISTÉRIO DA SAÚDE, 2006, p.13).
} 

instersetoriais devem complementar a integralidade da atenção no SUS e compor as estratégias desse modelo de atenção.

A saúde sexual e reprodutiva está fundamentada na garantia e no reconhecimento dos adolescentes enquanto sujeitos de direitos sexuais e reprodutivos, capazes de assumir com responsabilidade e autonomia as próprias escolhas. Dessa maneira:

Garantir os direitos reprodutivos a adolescentes e jovens, de ambos os sexos, no contexto dessa Política, significa assegurar, em todos os casos, as condições de escolha para aqueles que não querem engravidar ou querem planejar uma gravidez, como também a assistência ao pré-natal, ao parto e ao puerpério, que deve ser assegurada de modo irrestrito, de maneira que a gravidez possa ser desejada, planejada e vivenciada de maneira saudável (BRASIL, MINISTÉRIO DA SAÚDE, 2006, p. 26).

Para tanto, cabe aos serviços de saúde a prestação de uma assistência de qualidade e o desenvolvimento de ações educativas que abordem a saúde sexual e reprodutiva, os métodos contraceptivos e preservativos, oferecendo um serviço de contracepção e planejamento familiar específico para adolescentes e com acesso facilitado a estes.

A questão da redução da morbimortalidade por causas externas envolve o trabalho de prevenção de acidentes e violência na adolescência e juventude por meio de um conjunto de ações educativas voltadas para a mudança de atitudes e o desenvolvimento de habilidades. Conforme a Política Nacional de Redução da Morbimortalidade por Acidentes e Violências do Ministério da Saúde, "as ações a serem desenvolvidas são aquelas inerentes à promoção da saúde e voltadas a evitar a ocorrência de violências e acidentes, incluindo as ações destinadas ao tratamento das vítimas, nestas compreendidas as ações destinadas a impedir as seqüelas e as mortes resultantes desses eventos" (BRASIL, MINISTÉRIO DA SAÚDE, 2006, p. 30). Essa demanda deve ser atendida por meio das ações intersetoriais que compreendem um trabalho de prevenção e redução das vulnerabilidades, além de prever a assistência a agravos relacionados ao uso do álcool e outras drogas, fatores de risco para acidentes de trânsito.

Como se pode observar, essas questões prioritárias, consideradas eixos de ação da Política de Saúde do Adolescente e Jovem, pressupõem o fortalecimento da atenção básica, ou seja, considerando a necessidade de implementar na saúde "um novo olhar para o adolescente e jovem", essa política destaca a Atenção Básica como estratégia prioritária na atenção à saúde do adolescente ${ }^{7}$. De acordo com tal política:

\footnotetext{
7 "A Atenção Básica caracteriza-se por um conjunto de ações de saúde, no âmbito individual e coletivo, que abrangem a promoção e a proteção da saúde, a prevenção de agravos, o diagnóstico, o tratamento, a reabilitação e a manutenção da saúde. É desenvolvida por meio do exercício de práticas gerenciais e sanitárias democráticas e participativas, dirigidas a populações de territórios bem delimitados, pelas quais assume a responsabilidade sanitária" ( BRASIL, MINISTÉRIO DA SAÚDE, 200, p. 20).
} 
A Atenção Básica deve, em especial, realizar o acompanhamento do crescimento e desenvolvimento (C\&D), garantir a atenção à saúde sexual e saúde reprodutiva de ambos os sexos, incluindo o acesso a métodos contraceptivos, articular ações de redução da morbimortalidade por causas externas, e desenvolver ações educativas com grupos. (BRASIL, MINISTÉRIO DA SAÚDE, 2006, p. 21).

Nessa perspectiva, o desafio para gestores e profissionais de saúde é qualificar as unidades básicas de saúde para que ofereçam uma atenção resolutiva e de qualidade, o que abrange a construção de uma rede de proteção social que garanta os direitos dessa população, por meio de parcerias intersetoriais e atividades extramuros.

No entanto, as dificuldades enfrentadas atualmente pelos serviços de saúde, especialmente os da rede de atenção básica, se colocam na contramão da efetivação da atenção integral à saúde de adolescentes, destacando-se nesse âmbito a ausência de profissionais capacitados para o atendimento ao adolescente, a ausência de uma demanda organizada " em consonância com a estratégia da territorialidade" voltada para o desenvolvimento de ações como: busca ativa, captação precoce de adolescentes grávidas, estratégias de trabalho com grupos de adolescentes na perspectiva do protagonismo juvenil.

$\mathrm{Na}$ experiência profissional e de pesquisa na rede de atenção básica do município de Maceió, destaca-se a necessidade de uma análise situacional da saúde de adolescentes de modo a subsidiar a construção dos indicadores de saúde do adolescente e a elaboração do Protocolo de Assistência à Saúde do Adolescente para normatizar a rotina de atendimento desse grupo etário nas Unidades básicas de saúde e demais serviços da rede SUS. Sob tais aspectos, reside o desafio inerente à operacionalização dessa política, a qual envolve o compromisso de vincular a atenção a este grupo populacional à rede de atenção do SUS e às ações de rotina do SUS em todos os seus níveis.

Outra questão importante refere-se à relação entre saúde e participação juvenil. Nos contornos dessa política, o fortalecimento dos vínculos familiares e comunitários por meio de ações de promoção e educação em saúde e prevenção de agravos revela-se uma estratégia de impacto no sentido de minimizar as iniquidades relacionadas ao preconceito, à exclusão e à discriminação.

A promoção da saúde de adolescentes e jovens precisa incorporar ações no serviço de saúde e intersetoriais no combate às desigualdades e iniqüidades relacionadas à raça, etnia, gênero e orientação sexual, e a outras formas de exclusão e discriminação. Embora estas sejam questões do âmbito social e cultural, o seu impacto sobre o bem-estar psicológico e emocional - e, inclusive, sobre a dimensão física da saúde pode ser devastador. Iniciativas locais que fomentam a participação juvenil, a convivência comunitária, a inserção social, as atividades culturais e esportivas devem ser apoiadas 

e valorizadas. Os serviços de saúde devem estabelecer mecanismos de referência e contra-referência com essas iniciativas, quer sejam governamentais ou não (BRASIL, MINISTÉRIO DA SAÚDE, 2006, p. 22).

Tal como se pode observar, além do fortalecimento da atenção básica, essa política considera a promoção e educação em saúde como estratégias fundamentais de superação das desigualdades e exercício da cidadania por parte da população jovem. A promoção da saúde no âmbito comunitário é colocada como responsabilidade dos serviços de saúde, que deverão estimular a participação juvenil ativa, propiciando oportunidades para que os adolescentes e os jovens desenvolvam sua autonomia, se mobilizem e definam suas próprias prioridades para atuação na comunidade, envolvendo seus familiares e pares.

Contudo, essa questão nos leva a considerar algumas contradições. Atualmente, observam-se algumas dificuldades para o desenvolvimento de estratégias de trabalho com grupos de adolescentes dentro do enfoque de promoção da saúde preconizado pela Política.

As iniciativas na área de promoção da saúde de adolescentes e jovens são limitadas e, às vezes, inviabilizadas por conta da carência de recursos materiais e infraestrutura das unidades de saúde. Alguns problemas são apresentados pelos profissionais de saúde, entre os quais: a falta de espaço físico adequado, a falta de material educativo, insumos etc. Além disso, acrescenta-se a ausência de uma rede de serviços de referência e contrarreferência para dar suporte às referidas unidades. As ações são fragmentadas e assistemáticas, pois muitas vezes limitam-se ao calendário de datas comemorativas e campanhas de saúde pontuais.

A intersetorialidade defendida pela política de saúde é prejudicada pela ausência de um planejamento articulado que consiga envolver todas as unidades da rede de atenção básica e parcerias importantes como a escola, acarretando uma duplicidade de ações. Além disso, as atividades desenvolvidas dentro dessas unidades, na maioria das vezes, limitam-se às palestras em salas de espera e à abordagem grupal para distribuição de preservativos, que não costumam atrair a atenção do público adolescente. A participação juvenil é restrita e não se efetiva nas instâncias de planejamento, execução e avaliação das ações de saúde e controle social do SUS.

Por outro lado, cabe-nos questionar: em que medida as ações de promoção de saúde, desenvolvidas a partir de estratégias de protagonismo juvenil e de formação de redes, podem contribuir para superação das desigualdades sociais? O protagonismo juvenil revela-se condição para cidadania e alcance dos direitos para adolescentes?

No eixo de análise dessas questões, torna-se necessário considerar algumas contradições.

Sem dúvida, o paradigma da proteção integral regulamentado pelo Estatuto se revela um importante avanço no sentido de delimitar uma política pública voltada para o atendimento às necessidades básicas da infância e adolescência, inserindoa no campo dos direitos políticos e sociais.

No entanto, "as opções do Estado têm permanecido no âmbito de ações emergenciais, focais, descontínuas e desarticuladas em contraposição às exigências 

do Adolescente" (MALTA, 2008). As respostas do Estado são qualificadas como respostas restritas aos efeitos e conseqüências das condições de degradação das formas de reprodução social de crianças, adolescentes e suas famílias.

Desse modo, a natureza do Estado de tratar as conseqüências e não as causas dos fenômenos sociais vem contribuindo para o agravamento do quadro de desproteção social e violação dos direitos à vida, à escolarização, à saúde, à moradia e à convivência familiar e comunitária. Ao mesmo tempo, "Essas condições de vida e sobrevivência refletem-se em perversos e contínuos processos de desumanização, naturalizados por parte do Estado e da sociedade, apesar da extrema visibilidade de abandono social e institucional"(MALTA, 2008, s/p) .

Nesse sentido, as estratégias colocadas pelo Estado por meio das políticas sociais não dão conta de resolver o problema da desigualdade, pois a desigualdade decorre da lógica imanente ao Estado capitalista.

Podemos então dizer que o Estado representa a lógica do capital. Com isso, "o Estado é a forma como os indivíduos de uma classe dominante fazem valer os seus interesses, sob a máscara da justiça e da soberania popular em base de igualdade" (SILVA, apud RAPOSO, 2003, p. 20). Sob essa óptica, a cidadania é traduzida na lógica do Estado capitalista e, nesse sentido, compreende uma cidadania minimalista. De acordo com a concepção liberal de cidadania, os direitos se revelam como obrigações do Estado para garantir um mínimo de segurança e bem-estar à sociedade. Assim, a cidadania liberal assume uma funcionalidade no sistema capitalista, na medida em que serve para ocultar a existência das relações contraditórias de exploração. Todavia, na perspectiva marxiana, a propriedade privada dá centralidade e fundamento aos direitos humanos e estes [direitos] são, para Marx, o resultado da cultura do mundo burguês. Acerca da crítica sobre os direitos humanos, Marx, em A Questão Judaica, já dizia: "Nenhum dos direitos humanos ultrapassa o egoísmo do homem, do homem como membro da sociedade burguesa, isto é, do indivíduo voltado para si mesmo, para seu interesse particular, em sua arbitrariedade privada, dissociado da comunidade"(MARX, 1991).

Portanto, de acordo com a teoria de Marx, a lógica da acumulação e da valorização do capital pressupõe a contradição entre a instauração da igualdade jurídico-política e a desigualdade social. Nesse sentido, o debate atual sobre a cidadania se inscreve na "dualidade de lógicas" ${ }^{8}$ do Estado: a do capitalismo e a da democracia, contraditórias entre si e complementares. Sob este ponto de vista, a lógica do capital precisa da lógica democrática, uma vez que a democracia e a cidadania constituem elementos significativos para o Estado legitimar o seu poder e a sua dominação.

A cidadania não resiste à lógica das determinações estruturais da relação capital-trabalho; "a igualdade jurídico-política por si só não é suficiente para equilibrar a profunda desigualdade entre o econômico e o social, pois acima da

\footnotetext{
${ }^{8} \mathrm{~A}$ "dualidade de lógicas do Estado" é analisada por Carlos Montaño em seu texto: "Das lógicas do Estado às lógicas da sociedade civil: Estado e Terceiro Setor em questão", In: Revista Serviço Social e Sociedade n 59, São Paulo, Cortez Editora, 1999.
} 

condição de cidadania, está o princípio da propriedade privada..." (TAVARES, 2006, $\mathrm{s} / \mathrm{p})$.

Essas breves considerações sobre a concepção de direitos humanos e cidadania na sociedade capitalista suscitam a importância do referencial críticoanalítico para desvelar essas questões na realidade contemporânea. Ainda que estejam definidos os direitos humanos fundamentais da infância e juventude brasileiras - a partir do Estatuto da Criança e do Adolescente -, verifica-se que no cotidiano esses direitos estão longe de ser garantidos. Sobre este aspecto, vale ressaltar que as dimensões da violação do direito à saúde do adolescente se inscrevem na complexa crise do capitalismo contemporâneo. Ou seja, na medida em que se operam as transformações e mudanças em nível do Estado, é impossível ignorar a tensão existente entre o crescente interesse pelos direitos humanos e sua constante violação.

\section{Considerações Finais}

Em face das atuais mudanças observadas na relação Estado/Sociedade, a desresponsabilização do Estado e a desconstrução de valores éticos e dos direitos humanos configuram as marcas de violação de direitos, no sentido de uma violência estrutural, nos contornos da exclusão social e fragmentação do homem. Nesse sentido, a violência estrutural aqui aludida circunscreve o contexto de negação dos direitos humanos fundamentais, como a vida, a liberdade e a segurança.

De acordo com o Estatuto da Criança e do Adolescente (ECA), são três as condições básicas para que um fato seja caracterizado como violação de direito: a existência de um sujeito até 18 anos que tenha sofrido a violação; a prática de uma ação contrária ao direito assegurado ou mesmo a omissão e ameaça ante o cumprimento desses direitos; um responsável pela ação ou omissão que resultou no descumprimento do direito.

Especialmente no âmbito da saúde, são identificadas algumas formas de violação desse direito, como se verifica com o seu não cumprimento. Para se definir as violações a esse direito, o SIPIA (Sistema de Informação para a Infância e Adolescência $)^{9}$ considera a necessidade de um tratamento rigoroso para a explicação de cada uma das formas possíveis de violação do direito à saúde de crianças e adolescentes. De forma sucinta citamos algumas delas, fazendo referência ao dispositivo da lei que é violado.

- Não atendimento médico: (falta de atendimento pré e perinatal (Art. 8º); falta de atendimento emergencial (Art. 11); falta de atendimento especializado (Art. 11); falta de acompanhamento médico de rotina (Art. 11); falta de equipamento). (Art. 11).

- Atendimento médico deficiente (aplica-se aos casos em que são provocados danos à vida e à saúde da criança ou adolescente por incorreção ou deficiência no atendimento prestado); cirurgias desnecessárias, danos cirúr-

\footnotetext{
9 Sistema de Informações para a Infância e Adolescência consiste num sistema de registro e tratamento de informações sobre a garantia dos direitos fundamentais preconizados pelo Estatuto da Criança e do Adolescente (Lei 8.069/90).
} 
gicos, esterilização de adolescente, intoxicação medicamentosa, interrupção de tratamento, diagnóstico incorreto, tratamento incorreto, falta de medicamento, falta de precedência no atendimento à criança e ao adolescente, falta de orientação aos pais no tratamento da criança (Art. $4^{\circ}$ ), negligência no atendimento. Além disso, são considerados danos à vida e à saúde de crianças e adolescentes: omissão de socorro, recusa de atendimento médico por razões filosóficas, ideológicas ou religiosas, falta de registro e/ ou denúncia de maus-tratos (Art. 13), falta de notificação de doenças infectocontagiosas, falta de saneamento básico etc.

- Práticas hospitalares e ambulatoriais irregulares: tratam-se de ações por parte de hospitais e ambulatórios no que se refere a direitos de registro, de identificação e de acompanhamento; proibição de permanência do responsável em caso de internação (Art. 12), falta de alojamento conjunto no nascimento (Art. 10, inciso), inexistência ou não preenchimento de prontuário, não fornecimento de declaração de nascimento, entre outros.

- Irregularidades na garantia da alimentação: são as ações ou omissões do Estado ou da sociedade que acarretam riscos ou danos à criança ou ao adolescente, por falta de alimentação e nutrição ou por suas más condições (Art. 9).

- Atos atentatórios à vida: são ações deliberadas que atentam contra a vida de crianças e adolescentes: homicídio, tentativa de homicídio, cirurgias com fins ilícitos. (BRASIL, MINISTÉRIO DA JUSTIÇA, 1997, p. 18-19).

A partir da caracterização das formas de violação do direito à saúde [infância e adolescência], é que se pode associar a violação de direitos ao problema da vulnerabilidade a que estão sujeitos os adolescentes e jovens no contexto atual da sociedade brasileira. Sob este aspecto, podemos evidenciar a importância dos fatores externos, os quais constituem uma poderosa influência sobre o modo como adolescentes e, também, os jovens pensam e se comportam; os elementos que compõem o meio em que eles vivem: como os veículos de comunicação de massa, a indústria do entretenimento, as instituições comunitárias e religiosas, e os sistemas legal e político (BRASIL, MINISTÉRIO DA SAÚDE, 2006).

Ainda no campo das vulnerabilidades estão inseridas as necessidades de grande importância para o desenvolvimento desse segmento, representadas pelo acesso à educação formal, aos serviços de saúde, às atividades recreativas, ao desenvolvimento de talentos e vocações e às oportunidades de trabalho. Muito frequentemente, a pobreza, o preconceito, enfim, as situações de desproteção social privam o adolescente e o jovem de tais acessos.

Acresce ainda a enorme exposição do adolescente e do jovem aos riscos associados à violência, ao consumo de álcool e drogas, aos distúrbios sociais, às migrações e aos conflitos armados, somando-se, também, a curiosidade de quem está descobrindo o mundo e, às vezes, sente o desejo de experimentar tudo o que se apresenta como novo.

O quadro dessas vulnerabilidades é traduzido pelos problemas mais comuns que acometem esse grupo etário - entre os quais podemos citar a gravidez na ado- 

lescência, o alcoolismo, a dependência química, além dos mais variados tipos de agravos à saúde do adolescente e jovem.

Com base no Perfil Analítico das Mães Adolescentes ${ }^{10}$ (10 a 19 anos) do Município de Maceió verificamos o descompasso entre as prerrogativas dos direitos assumidos no ECA e a realidade concreta. No ano de 2006, o município registrou 3.628 nascimentos de mães na faixa de 10 a 19 anos, sendo 3.465 (95,5\%) de mães de 15 a 19 anos. O Baixo Peso ao Nascer e o Parto Cesário revelaram tendência crescente. A idade menor que 15 anos, pré-natal com menos de sete (7) consultas e duração da gestação menor que trinta e sete (37) semanas foram causas de baixo peso ao nascer.

No ano de 2005, de acordo com o Perfil Epidemiológico de Maceió ${ }^{11}$, dentre os principais agravos na faixa etária de 10 a 19 anos estavam as Doenças Sexualmente Transmissíveis, com um total de 246 casos somente na faixa etária de 10 a 19 anos, a hepatite viral com 73 casos notificados e a tuberculose com 59 casos notificados.

Diante desse quadro, alguns questionamentos parecem desafiar-nos: a afirmação dos direitos fundamentais e a formulação de políticas sociais para a infância e juventude no Brasil correspondem à efetivação da cidadania para adolescentes e jovens? Quais são as possibilidades ou perspectivas de atuação para os profissionais no âmbito das políticas sociais?

Tal como se pode ver, a violência estrutural e a violação dos direitos configuram as situações de vulnerabilidade na adolescência e nos remetem ao debate mais amplo sobre a questão da garantia dos direitos da infância e adolescência, por meio da política de proteção de atenção integral à saúde. Remetem, portanto, ao debate sobre a questão da cidadania, o que nos faz considerar algumas contradições.

Em face da aprovação do Estatuto da Criança e do Adolescente concomitantemente às mudanças no padrão de proteção social, temos uma ampliação dos direitos da população infanto-juvenil por parte do Estado, da família e da sociedade e, ao mesmo tempo, convivemos com a constante violação dos direitos individuais e coletivos adquiridos no ordenamento legal.

O paradigma da garantia dos direitos, que se refere à condição de cidadania das crianças e adolescentes, se inscreve na ordem dos limites da normativa jurídica e da política de atendimento. Ou seja, ao tempo que os direitos são proclamados e conquistados, no Brasil, revela-se um quadro extremamente grave de violação de direitos, traduzido pela situação de vulnerabilidade e desproteção social em que vivem a infância e a juventude brasileiras.

Assim, a gestão e o funcionamento do sistema de garantia de direitos encontram-se, atualmente, ameaçados pelos limites de caráter estrutural e conjuntural devido às tendências de flexibilização e focalização das políticas públicas

\footnotetext{
${ }^{10}$ Perfil Analítico das Mães Adolescentes (10-19 anos) - Análise da Situação de Saúde no Ano de 2006. Estudo ${ }^{10}$ Perfil Analítico das Mães Adolescentes (10-19 anos) - Aná
realizado pela Secretaria Municipal de Saúde de Maceió.

11 "Perfil Epidemiológico é a combinação do conceito de Perfil e Epidemiologia" (SMSMACEIÓ, 2007, p. 1). Trata-se de um retrato, desenho do objeto da Epidemiologia, a qual trata dos fatores e efeitos, englobando aspectos biológicos, sociais, econômicos, ambientais, de higiene, nutricionais, demográficos, educacionais, culturais etc.
} 

- conforme as exigências de ajustamento estrutural - impostas por uma política econômica de cunho neoliberal.

Dessa maneira, em tempos de hegemonia neoliberal, as instituições políticas, entre elas o Estado, veem-se ameaçadas na sua existência. O que podemos constatar é a erosão das bases políticas de sustentação do Estado que entra em crise. E, essa crise do Estado repercute no redimensionamento da cidadania, no sentido da restrição de direitos, sem condições mesmo de garantir os mínimos sociais para os segmentos vulnerabilizados. No âmbito da saúde, "(...) as políticas de redução do Estado, as privatizações e o novo papel desempenhado pelo mercado como provedor das necessidades de saúde" (NOGUEIRA, 2006, p. 233) são tendências que se configuram como verdadeiros entraves ao processo de implantação do SUS.

Diante disso, "há que se considerar a situação adversa às propostas de democracia social, decorrentes dos ajustes macroeconômicos, da década de 90, no Brasil. As políticas de redução do Estado, as privatizações e o novo papel desempenhado pelo mercado como provedor das necessidades de saúde foram a pedra de toque das dificuldades que ora se apresentam" (NOGUEIRA, 2006, p. 233). Produzindo um quadro paradoxal que se concretiza no processo de aviltamento das políticas públicas e privação de direitos básicos (CARVALHO, 1994, p. 54).

Constata-se que a crise do capitalismo contemporâneo impõe uma nova lógica de reestruturação produtiva com profundas inflexões na esfera da regulação/ reprodução social, provocando fortes rebatimentos sobre as políticas sociais. "A reestruturação produtiva, mediante as políticas macroeconômicas que a orientam, especialmente pela flexibilização, imprime novas estratégias para alcançar o objetivo da acumulação" (TAVARES, 2006, s/p). Nesse sentido é que se pode dizer que "os ciclos econômicos balizam as possibilidades e limites da política social" (BEHRING, 1998, p. 174).

Sob este parâmetro analítico há de se ultrapassar a concepção de política social como direito de cidadania e elemento redistributivo, pois essa perspectiva compõe parâmetros analíticos insuficientes e mitificadores da realidade. Para tanto, é necessário ter uma visão mais realista sobre os contornos da Política Social, a partir da apreensão das múltiplas determinações que integram a definição dessas políticas, para, assim, empreender uma ação política mais consistente no espaço contraditório do Estado (BEHRING, 1998, p.174). Por tudo isso é que se pode afirmar: "as possibilidades e limites das políticas sociais são determinadas principalmente pela economia" (TAVARES, 2006), no contexto da atual crise do capital.

No âmbito da Saúde, as tendências atuais de focalização e privatização das políticas sociais apontam para a restrição da universalidade e da integralidade (princípios do SUS), impostas pela lógica de desresponsabilização do Estado, a qual se evidencia na precarização do Sistema Único de Saúde (SUS). Como enfrentar os desafios postos por essa realidade? Quais as perspectivas de atuação para os profissionais que atuam na formulação e execução das políticas sociais?

Orientados pela perspectiva da totalidade, é possível entender a política como meio e não como fim (TAVARES, 2006). Com base nessa perspectiva é que podemos compreender o terreno em que se movem as políticas sociais e problematizar a crise do capitalismo; só por meio dessa perspectiva crítico-analítica é 
REVISTA Em Pauta

Volume 6 - Número 23 - Julho de 2009

\} A Política de Atenção Integral à Saúde do Adolescente e Jovem: uma perspectiva de garantia de direito à saúde? - RAPOSO, C. \} que se pode entender a lógica complexa da realidade e saber para onde "sopram os ventos" (CARVALHO, 1994) da crise das políticas sociais no cenário contemporâneo. A partir desse campo de análise será possível colocar os direitos dos adolescentes e da juventude no terreno sócio-histórico da vida e desse modo pensar a efetiva garantia de direito à saúde, motivo deste estudo. 


\section{REFERÊNCIAS BIBLIOGRÁFICAS}

BRASIL. Estatuto da Criança e do Adolescente. Lei 8.069/90. São Paulo: Ministério da Justiça, 1990.

BRASIL, Ministério da Justiça. Sistema de Informação para Infância e Adolescência - SIPIA. Manual do Usuário. Brasília: Ministério da Justiça, 1997.

BRASIL, Ministério da Saúde. Notificação de maus-tratos contra crianças e adolescentes pelos profissionais de saúde "um passo a mais na cidadania em saúde". Brasília: Ministério da Saúde, Secretaria de Assistência à Saúde, 2002.

BRASIL, Ministério da Saúde. Secretaria de Atenção à Saúde. Área de Saúde do Adolescente e do Jovem. Brasília: Ministério da Saúde, 2005.

BRASIL, Ministério da Saúde. Área Técnica de Saúde do Adolescente e Jovem. Política Nacional de Atenção Integral à Saúde do Adolescente e Jovem. Brasília, 2006. Disponível em http//www.saude.gov.br. Acesso em 6 de março de 2009. BEHRING, E. R. Política social no capitalismo tardio. São Paulo: Cortez, 1998. CARVALHO, A. M. P. Políticas sociais em tempo de crise - Para onde sopram os ventos contemporâneos. In: Infância e Adolescência em discussão. Núcleo Cearense de Estudos e Pesquisas sobre a Infância - NUCEPEC. Fortaleza: UFC/CBIA, 1994. CRESS, Conselho Regional de Serviço Social 16 $6^{\text {a }}$ Região/AL. Coletânea de Leis. Alagoas: CRESS, 2002.

CURY, Munir et alii. Estatuto da Criança e do Adolescente comentado. Comentários jurídicos e sociais. 5ª Edição. São Paulo: Malheiros, 2002.

MALTA, C. A ação do Estado ante a situação de desumanidade de crianças e adolescentes: focalização e tratamento das emergências. XI Encontro de Pesquisadores em Serviço Social - ENPESS, dezembro, 2008. Maranhão. Mimeo.

MARX, Karl. A questão judaica. São Paulo: Ed. Moraes, 2a edição, 1991.

MONTAÑO, Carlos. Das lógicas do Estado às lógicas da sociedade civil: Estado e Terceiro Setor em questão. In: Revista Serviço Social e Sociedade, n. 59. São Paulo: Cortez Editora,1999.

MOTTA, A. E. Serviço Social na Contemporaneidade: A Questão Social e as perspectivas ético-políticas. XXIX Encontro Nacional do CEFSS/CRESS. Maceió: CEFSS/ CRESS, 2000. Mimeo.

NETTO, J. P. Cinco notas a propósito da "Questão Social". In: Temporalis, Revista da Associação Brasileira de Ensino e Pesquisa em Serviço Social, Ano II, n. 3, janeirojunho. Brasília: ABEPSS, 2001.

NOGUEIRA, Vera, M. R. MIOTO, Regina. C. T. Desafios atuais do Sistema Único de Saúde - SUS e as exigências para os assistentes sociais. MOTA, Ana Elizabete [et. alii] (orgs.). Serviço Social e Saúde: formação e trabalho profissional. São Paulo: OPAS, OMS, Ministério da Saúde, 2006.

RAPOSO, C. T. M. Infância e violência doméstica: tendências e perspectivas na defesa dos direitos da criança e adolescentes no Município de Maceió. Dissertação de mestrado. Recife: Programa de Pós-Graduação em Serviço Social, 2003. Mimeo. SECRETARIA MUNICIPAL DE SAÚDE DE MACEIÓ. Perfil analítico das mães adolescentes (10-9 anos): análise da situação de saúde no ano de 2006. Maceió: SMS, 2007. 


\section{REVISTA Em Pauta}

Volume 6 - Número 23 - Julho de 2009

\} A Política de Atenção Integral à Saúde do Adolescente e Jovem: uma perspectiva de garantia de direito à saúde? - RAPOSO, C. \} TAVARES, M.A. Trabalho e demandas sociais na reestruturação do capital. O Serviço Social entre a prática e a realidade. In: Temporalis 11. Recife: ABEPSS, 2006, JaneiroJunho.

Recebido em 20 de abril de 2009.

Aceito para publicação em 29 de maio de 2009. 